\title{
Newborn Cord Care Practices amongst Mothers in Yenagoa Local Government Area, Bayelsa State, Nigeria
}

\author{
Peace Ibo Opara ${ }^{1 *}$, Tamunopriye Jaja ${ }^{1}$, Doris Atibi Dotimi ${ }^{2}$, Balafama Abinye Alex-Hart ${ }^{1}$ \\ ${ }^{1}$ Department of Paediatrics, University of Port Harcourt Teaching Hospital, Port Harcourt, Nigeria; ${ }^{2}$ Department of Community \\ Health, School of Health Technology, Ogbia, Nigeria. \\ Email: *peaceibo@yahoo.com.au
}

Received October $5^{\text {th }}, 2011$; revised November $20^{\text {th }}, 2011$; accepted December $7^{\text {th }}, 2011$

\begin{abstract}
Background: Clean cord care is one of the essential newborn care practices recommended by the World Health Organisation to reduce morbidity and mortality amongst the World's newborns. Despite this, cord infections are still prevalent in developing countries because of the high rates of unhygienic cord care practices. The study aimed to explore cord care practices in our environment and identify areas for intervention. Methods: This was a cross-sectional study carried out amongst mothers attending three primary health care facilities with their infants in Yenagoa Local Government Area of Bayelsa State, Nigeria. Simple structured questionnaires were used to obtain information concerning the ages and sexes of babies, place of antenatal care and birth, treatments applied to the umbilical cord stump and the socioeconomic status of the parents. Data were analysed using SPSS version 16.0. Results: Two hundred and twenty one mothers participated in the study. The infants were aged 0 - 6 months with a male to female ratio of 1:1. Fifty four (24.4\%) of mothers were of high social class. Cord care was done by grandmothers in 107 (48.4\%) and mothers in $89(40.3 \%)$ of babies. Sixty four (29.0\%) mothers had their babies cord cleaned with Methylated spirit alone while 138 (62.4\%) cleaned with Methylated spirit and then applied other substances including antibiotic ointments and herbs. Maternal education, social class of parents and place of delivery were significantly associated with application of potentially harmful substances to the cord, $(\mathrm{p}=0.049,0.010$ and 0.030 respectively). The commonest sources of information on cord care were nurses in $99(44.8 \%)$ and grandmothers in $44(19.9 \%)$. Conclusion: There is still a high rate of use of potentially harmful substances for cord care. All heath workers should participate in educating, mothers and grandmothers about optimal cord care.
\end{abstract}

Keywords: Newborn; Cord Care; Practices

\section{Introduction}

The World Health Organization recommends improving newborn care practices at birth in order to reduce morbidity and mortality. These have been described as essential newborn care (ENC) practices [1-3]. One of these essential practices is clean cord care which is very important in preventing early neonatal infections [2]. The basis of cord care, as we know it today, has evolved through many years of traditional and cultural customs.

The cutting of the cord is achieved in various ways throughout the world. Examples include; the Gadsup midwives of New Guinea, who cut the umbilical cord with a bamboo knife heated over an open fire and a similar practice in Guatemala, where scissors are heated over a candle made from grease [4]. These may seem strange, but there is an obvious attempt to avoid infection throughout.

\footnotetext{
"Corresponding author.
}

Care of the cord following delivery is even more varied but once again the underlying aim is to avoid infections to the cord and the surrounding area. Treatments range from the application of ashes and fresh colostrum in Kenya, to coconut oils and flowers by the American Samoans [4]. The current World Health Organization (WHO) recommendations for developing countries, promote dry cord care under routine circumstances but acknowledge that antiseptics may be helpful when harmful, unhygienic, traditional practices place newborns at increased risk for omphalitis [3,5]. Apart from plain water, the use of other products for cleaning the cord may interrupt the natural healing process [6,7]. The use of sterile cotton wool soaked in either methylated spirit, chlorhexidine or gentian violet (1\%) to clean the cord is however still being practiced widely especially in developing countries where infection rates are high [8-10].

Cord care practices may directly contribute to infections in the newborn which account for a large proportion 
of the four million annual global neonatal deaths [11]. Cord infections are more prevalent in developing countries because of the high rates of unhygienic cord care practices [4,12]. Some of these practices which have been reported especially in the rural areas, include the use of traditional cord dressings like cow dung, herbal preparations, ash, mud, coconut oil etc which are usually contaminated and serve as sources of infection $[4,12]$. The aim of this study was to determine cord care practices prevalent amongst care givers, including mothers and other female house hold members in Yenagoa Local Government Area of Bayelsa State in Southern Nigeria and to determine the need for proper education.

\section{Methods}

The study was carried out at Yenagoa Local Government Area (LGA) of Bayelsa State. The state is in Southern Nigeria in the core Niger Delta region, on the coast between Delta State and Rivers State. The state was created in 1996 from part of Rivers State and thus, it is one the newest states of the Nigerian Federation [13]. Bayelsa has a riverine setting. A lot of her communities are almost (and in some cases) completely surrounded by water, making these communities inaccessible by road [14]. The state has one of the largest crude oil and natural gas deposits in Nigeria. As a result, petroleum production is extensive in the state. However, because of the difficult terrain, majority of its citizens live in poverty and are mainly rural dwellers. This has also resulted in lack of adequate transportation, health, education and other infrastructure. Yenagoa is one of eight LGAs in Bayelsa State with Its headquarters in the town of Yenagoa (the State capital) in the south of the area. The LGA has an area of $706 \mathrm{~km}^{2}$ and a population of approximately 353,344 at the 2006 census [14]. The status of Yenagoa as the state capital has attracted people from all over the state. It is also one of the most easily accessible parts of the state; one of the few areas that can be accessed by road. The multi-ethnic nature of the LGA and easy accessibility necessitated its choice for this study.

Yenagoa LGA is geo-politically divided into 15 wards. There are 27 health centres spread across these wards. Stratified Random Sampling Technique was used to select 3 of the 15 wards and simple random technique was used to select one health centre from each of the three wards selected. Each of these health centres runs immunization services once weekly. The population of study was Nursing Mothers attending these Primary Health Care facilities for routine immunization of their children.

The data were collected over a period of four weeks. Mothers who had come with children 0 - 6 months and who gave consent to be included in the study were recruited on immunization days. A simple structured questionnaire was used for data collection. Final year students of the School of Heath Technology were trained to interview mothers and complete the questionnaires under the supervision of the Investigators. Information obtained included age of mother, educational status and occupation of both parents, age and sex of the index child, place of antenatal care and delivery, instruments used to cut umbilical cord, substances used for cord care, problems encountered in the care of the cord, time to cord separation, persons involved in care of the cord and source of information on cord care. Information on cord care was based on mother's last delivery i.e. the index baby. Questionnaires were retrieved by investigators as soon as they were filled. Respondents were not allowed to leave the venue with the questionnaires to avoid bias.

Socioeconomic status was determined based on the method by Olusanya et al. [15].

Data collected were entered into a Microsoft excel spread sheet and analyzed using SPSS version 16.0. Results were expressed as rates and proportions. Chi-square statistics were used to test for significance. Level of significance was set at a $\mathrm{p}$ value of less than or equal to 0.05 .

\section{Results}

Two hundred and twenty one mothers with children aged 0 to 6 months participated in the study. The males were 111 while the females were 110 in number giving a male to female ratio of $1: 1$. One hundred and fifty three (69.2\%) mothers were aged below 30 years.

One hundred and fifty eight (71.5\%) mothers had at least secondary education. Fifty four (24.4\%) mothers were in the high social class, while 65 (29.4\%) and 102 (46.2\%) were of middle and low social classes respectively. Maternal education and social class of the family were significantly associated with application of potentially harmful substances, $(\mathrm{p}=0.049$ and 0.010 respectively) with the less educated and lower social classes more likely to use potentially harmful substances.

One hundred and thirty mothers (58.8\%) received antenatal care for index baby from government hospitals and private clinics while 119 (53.8\%) delivered in such hospitals. Table 1 shows the place of antenatal care and delivery. Place of delivery was significantly associated with application of substances other than Methylated spirit to the cord $\left(\chi^{2}=1.260, \mathrm{p}=0.030\right)$.

Baby's cord was cut commonly with surgical blade and new razor blade in 84 (38.0\%) and 80 (36.2\%) of cases respectively. Cord clamp and black hair thread were the commonest items used in tying the cord. Table $\mathbf{2}$ shows the instrument used in cutting the cord and tying the cord after delivery.

Cord care was done by grandmothers in 107 (48.4\%) and mothers in 89 (40.3\%) and was done a minimum of thrice daily in 117 (52.9\%) of babies. 
Table 1. Place of antenatal care and place of delivery of 221 mothers who participated in the study.

\begin{tabular}{lcc}
\hline Place of antenatal care & Number & Percent \\
\hline Private clinics & 31 & 14.0 \\
Teaching Hospital & 13 & 5.9 \\
General hospital & 51 & 23.1 \\
Health center & 35 & 15.8 \\
Maternity Home & 53 & 23.9 \\
Traditional birth attendants & 38 & 17.2 \\
Total & $\mathbf{2 2 1}$ & $\mathbf{1 0 0}$ \\
Place of delivery & & \\
Private clinics & 18 & 17.2 \\
Teaching hospital & 14 & 6.3 \\
General Hospital & 39 & 17.6 \\
Health center & 29 & 13.1 \\
Maternity Home & 33 & 14.9 \\
Traditional birth attendants/Home & 68 & 30.8 \\
Total & $\mathbf{2 2 1}$ & $\mathbf{1 0 0}$ \\
\hline
\end{tabular}

Table 2. Instruments reportedly used to cut and tie the cord by 221 mothers who participated in the study.

\begin{tabular}{lcc}
\hline Instruments used to cut cord & Number & Percent (\%) \\
\hline Surgical blade & 84 & 38.0 \\
New razor blade & 80 & 36.2 \\
Scissors & 46 & 20.8 \\
Old razor blade & 6 & 2.7 \\
Knife & 1 & 0.5 \\
Don't know & 4 & 1.8 \\
Total & $\mathbf{2 2 1}$ & $\mathbf{1 0 0}$ \\
Instruments to tie cord & & \\
Cord clamp & 120 & 54.3 \\
Hair thread & 91 & 41.1 \\
Cloth & 7 & 3.2 \\
Nothing & 3 & 1.4 \\
Total & $\mathbf{2 2 1}$ & $\mathbf{1 0 0}$ \\
\hline
\end{tabular}

Sixty four (29.0\%) mothers had their babies cord cleaned with only Methylated spirit while 138 (62.4\%) cleaned with Methylated spirit and applied other substances. One (5.9\%) mother allowed cord to dry without any application, Table 3 shows cord care practices by mothers and caregivers. The commonest substance applied to cord after cleaning was antibiotic ointment in 89 (40.2\%) of cases. Others were herbs/cow's urine 18
Table 3. Cord care practices among 221 mothers who participated in the study.

\begin{tabular}{lcc}
\hline Materials used to clean cord & Number & Percent \\
\hline Material & 64 & 29.0 \\
\hline Methylated spirit alone & 138 & 62.4 \\
Methylated spirit plus & 13 & 5.9 \\
Water & 4 & 1.8 \\
Herbs & 1 & 0.5 \\
Breast milk & 1 & 0.5 \\
Nothing & 221 & 100 \\
Total & & \\
\hline Substances applied after cleaning with & & \\
methylated spirit & Number & Percent \\
\hline Substance & 89 & 40.2 \\
\hline Antibiotic ointment & 18 & 8.1 \\
Herbs/cow urine & 18 & 8.1 \\
Oil/ Vaseline & 8 & 3.6 \\
Hot balms & 5 & 2.4 \\
Others (powder, chalk, tooth paste.) & $\mathbf{1 3 8}$ & $\mathbf{6 2 . 4}$ \\
Total & & \\
\hline & & \\
\hline
\end{tabular}

(8.1\%) and oils/vaseline 18 (8.1\%).

There was no significant difference in time of cord separation between those who used Methylated spirit alone and those who used Methylated spirit and other substances $\left(\chi^{2}=57.51, \mathrm{p}=0.933\right)$. The mean time to cord separation was $5.53 \pm 2.558$ (range 2 - 21 days). Cord problems were reported in $42(19.0 \%)$ babies (Table 4).

One hundred and eighty one (81.9\%) mothers had received information on cord care. The commonest sources of information were nurses in 99 (44.8\%) and grandmothers in 44 (19.9\%) (Table 5).

\section{Discussion}

The study shows that majority of the mothers used methylated spirit to clean the cord, although as many as $62.4 \%$ also used other substances in addition to methylated spirit. The use of methylated spirit is in keeping with the Nigerian protocol which supports its use for cleaning the cord and keeping it dry afterwards [16]. This also agrees with the current WHO recommendation for developing countries for use of antiseptics when harmful, unhygienic, traditional practices place newborns at increased risk for omphalitis [3,5]. Combining methylated spirit with other substances some of which may be 
Table 4. Cord problems reported by 221 mothers who participated in the study.

\begin{tabular}{lcc}
\hline Problems & Number & Percent \\
\hline Redness around base & 24 & 57.1 \\
Bleeding & 10 & 23.8 \\
Foul smell & 5 & 11.9 \\
Pus from cord & 3 & 7.1 \\
Total & $\mathbf{4 2}$ & $\mathbf{1 0 0 . 0}$ \\
\hline
\end{tabular}

Table 5. Source of information on cord care.

\begin{tabular}{lcc}
\hline Source & Number & Percent \\
\hline Nurses & 99 & 44.8 \\
Doctors & 18 & 8.1 \\
Books/media & 9 & 4.1 \\
Grandmothers & 44 & 19.9 \\
Others ( Community Health workers, & 12 & 5.4 \\
TBA, friends) & 39 & 17.6 \\
None & $\mathbf{2 2 1}$ & $\mathbf{1 0 0}$ \\
Total & & \\
\hline
\end{tabular}

harmful as shown in this study, however puts infants at risk for infections or other adverse effects of those substances.

Most of the mothers knew what was used to cut their babies cords and all were aware of what was used to tie the cord. Razor blades were used for cord cutting and hair thread for tying the cord even among some of those delivered in hospital settings. Similar findings were reported in a study in eastern Uganda [3]. Authors in that study reported that this may happen when materials are in short supply in health facilities but should be boiled before use. This was however not explored in this study. Old razor blades and cloth were also used on the cord in this study. These have grave implications for mothers and newborns, considering that neonatal tetanus is still prevalent in this region [17].

One hundred and thirty eight mothers/caregivers applied other substances to the cord after cleaning with methylated spirit, most popular of which were antibiotic ointments. Topical antiseptic and antimicrobial regimens for umbilical cord care were implemented widely in past decades, despite a lack of conclusive evidence that these regimens can reduce infection rates [18]. Most studies were conducted in settings where overall infection risk was low, and the main focuses of randomized trials comparing antiseptics and no antiseptics were secondary outcomes such as cord-separation time. It has been reported in many studies [19-22] that application of a vari- ety of topical antiseptics and antimicrobials increases the time to separation of the cord, relative to protocols promoting dry cord care or nonantiseptic treatment. However findings in this study showed that there was no significant difference in time to cord separation irrespective of what was applied to the cord. This may be due to the fact that majority of the mothers applied methylated spirit either alone or in combination with other substances and also probably due to errors in recall in this study by the mothers. In most of the other studies where time to cord separation was studied, neonates were followed up till cord separated [19-23].

Topical antimicrobials have also been associated with emergence of bacterial resistance and allergic contact dermatitis [24]. Other substances applied included herbs/ cow's urine, powders and oils. The use of these potentially harmful substances has been reported in other studies, and has been shown to increase the risk for newborn infections including neonatal tetanus $[4,12,25]$.

There was a significant association between maternal education and parental socioeconomic class and application of potentially harmful substances to the cord. These findings are in keeping with studies that show that the higher the level of maternal education, the better the health seeking behavior and thus exposure to better knowledge of child care practices [26,27]. However, this association with social class in the study contrasts with findings in other studies [3,5,28]. Some authors postulate that increasing social development predisposes mothers to transit to "modernistic" newborn practices which are wrongly perceived to be safe e.g. the use of breast milk substitutes and application of powder to the cord, while others report that increasing social class does not necessarily mean increase in family income and so may not affect health seeking or influence health practices $[3,28]$. Place of delivery was also significantly associated with application of substances other than methylated spirit to the cord. This finding is similar to that in other studies $[12,25]$ which show that mothers who deliver in recognized health facilities are more likely to practice better cord care.

Cord care was carried out more by grandmothers than mothers in this study. This is not strange as in Nigeria and most African societies; grandmothers are often present to help care for newborns. This has health implications for maternal and newborn health. A review of literature on grandmothers' roles in maternal and child health in non-western societies revealed that in virtually all cultures and communities, they have considerable knowledge and experience related to all aspects of maternal and child development and a strong commitment to promoting the well-being of children, their mothers and families. Grandmothers should therefore be a target group for health education on maternal and newborn care 
$[29,30]$.

Forty two (19\%) mothers reported cord problems in their infants. This figure may seem low but it is important to remember that only mothers with life infants were recruited, thus automatically excluding infants that had died from cord related problems. Reports show that a substantial proportion of neonatal deaths in developing countries occur from infections of the umbilical cord and Infants with neonatal tetanus often have concomitant cord infections which points to unclean delivery and poor cord care practices $[16,27,28]$. A study done in Northern Nigeria [12] showed similar rates of cord infections, again mortalities were not explored and data were based on recall like in this study. Authors in the Northern Nigerian study [12] postulated that mothers who did not report cord problems, may have said so for the fear of being seen as irresponsible. This may also be applicable in this study.

Information received by mothers on newborn care may influence their practice. In this study, nurses were the highest source of information on cord care. This is probably because in most antenatal clinics in our setting, nurses routinely give health talks, some of which may include teachings on cord care. Grandmothers featured next to nurses as sources of information. In Nigeria and most African societies, grandmothers are regarded as custodians of wisdom and are often responsible for passing on tradition including newborn and child care practices. Information passed may be good, outdated or potentially dangerous. Studies in Asia and Africa show that majority of grandmothers including the illiterate, are capable of learning new things and are very open to change even if it means abandoning certain traditions [29-31].

In conclusion, there is still a high rate of use of potentially harmful substances for cord care in our environment. There is a low rate of doctors involvement in health education of care givers on new born care practices. The grandmothers play an important role in new born care and should be a target group for health education to improve new born care practices in our environment.

\section{REFERENCES}

[1] G. L. Darmstardt, Z. A. Bhatta, S. Cousens, T. Adam, N. Walker, L. Bernis, et al., "Evidence Based Cost Effective Interventions; How Many Newborns Can We Save?” Lancet, Vol. 365, No. 9463, 2005, pp. 977-988. doi:10.1016/S0140-6736(05)71088-6

[2] D. R. Marsh, G. L. Darmstadt, J. Moore, P. Daly and D. Oot, A. Tinker, "Advancing Newborn Health and Survival in Developing Countries: A Conceptual Framework," Journal of Perinatology, Vol. 22, No. 7, 2002, pp. 572-576. doi:10.1038/sj.jp.7210793

[3] P. Waiswa, S. Peterson, G. Tomson and G. W. Pariyo, "Poor
Newborn Care Practices-A population Based Survey in Eastern Uganda,” BMC Pregnancy and Childbirth, Vol. 10, No. 9, 2010. http://creativecommons.org/licenses/by/2.0

[4] D. S. Perry, "The Umbilical Cord Care: Transcultural Care and Customs," Journal of Nurse-Midwifery, Vol. 27, No. 4, 1982, pp. 25-30. doi:10.1016/0091-2182(82)90166-5

[5] World Health Organization, "Care of the Umbilical Cord: A Review of the Evidence," In Maternal and Newborn Health/Safe Motherhood, Division of Reproductive Health (Technical Support), Family and Reproductive Health, World Health Organization, Geneva, 1998.

[6] J. Medves, "Cleaning Solutions and Bacterial Colonization in Promoting Healing and Early Separation of the Umbilical Cord in Healthy Newborns,” Canadian Journal of Public Health, Vol. 88, No. 6, 1997, pp. 380-382

[7] S. Trotter, "Skincare for the Newborn: Exploring the Potential Harm of Manufactured Products," Midwives Journal, Vol. 5, No. 11, 2002, pp. 376-378.

[8] C. Ronchera-Oms, C. Hernandez and N. V. Jimemez, “Antiseptic Cord Care Reduces Bacterial Colonization but Delays Cord Detachment," Archives of Disease in Childhood, Vol. 71, No. 1, 1994, p. F70. doi:10.1136/fn.71.1.F70

[9] I. G. Verber and F. S. Pagan, "What Cord Care, if Any?" Archives of Disease in Childhood, Vol. 68, No. 5, 1993, pp. 594-596. doi:10.1136/adc.68.5 Spec No.594

[10] L. C. Mullany, G. L. Darmstadt, S. K. Khatry, S. C. LeClerq, J. Katz and J. M. Tielsch, "Impact of Umbilical Cord Cleansing with 4.0\% Chlorhexidine on Time to Cord Separation among Newborns in Southern Nepal: A Cluster-Randomized, Community-Based Trial," Journal of $\mathrm{Ob}$ stetetric Gynecologic and Neonatal Nursing, Vol. 35, No. 1, 2006, pp. 123-128.

[11] R. E. Black, S. Cousens, H. L. Johnsons, J. E. Lawn, I. Rudan, D. G. Bassani, P. Jha, H. Campbell, C. F. Walker, R. Cibulskis, T. Eisele, L. Liu and C. Mathers, "Global Regional and Neonatal Causes of Child Mortality in 2008: A Systematic Analysis,” Lancet, Vol. 375, No. 3, 2010, pp. 1969-1987. doi:10.1016/S0140-6736(10)60549-1

[12] J. P. Ambe, M. Bello, S. J. Yahaya and B. A. Omotara, "Umbilical Cord Care Practices in Konduga Local Government Area of Borno State, North Eastern Nigeria,” The Internet Journal of Tropical Medicine, Vol. 5, No. 2, 2009.

http://www.ispub.com/journal/the_internet_journal_of_tr opical_medicine/volume_5_number_2_46

[13] Bayelsa State.

http://www.nigeriagalleria.com/Nigeria/States_Nigeria/B ayelsa_State.html

[14] United States Agency for International Development, "Nigeria Biodiversity and Tropical Forestry Assessment," USAID, 2008, p. 76.

http://pdf.usaid.gov/pdf_docs/PNADN536.pdf

[15] O. Olusanya. E. Okpere and M. Ezimokhai, “The Importance of Social Class in Voluntary Fertility Control in a Developing Country," West African Journal of Medicine, Vol. 3, No. 3, 1985, pp. 76-78.

[16] Federal Ministry of Health, Save the Children, "Saving 
newborn lives in Nigeria: Newborn health in the context of the Integrated Maternal, Newborn and Child Health strategy,” 2nd Edition, JHPIEGO, Abuja, 2011 pp. 41-47.

[17] N. A. Akani, A. R. Nte and R. S. Oruamabo, "Neonatal Tetanus in Nigeria: One Social Scourge Too Many!” Nigerian Journal of Paediatrics, Vol. 31, No. 1, 2004. pp. $1-9$.

[18] J. Zupan, P. Garner and A. A. A. Omari, "Topical Umbilical Cord Care at Birth," The Cochrane Database of Systematic Review, No. 3, 2004, Article No. CD001057. http://www2.cochrane.org/reviews/en/ab001057.html

[19] M. Magowan, A. Andrews, B. Pinder and S. Allen, "The Effect of an Antibiotic Spray on Umbilical Cord Separation Times," Nursing Times, Vol. 76, No. 42, 1980, p. 1841

[20] O. Smales, "A Comparison of Umbilical Cord Treatment in the Control of Superficial Infection," The New Zealand Medical Journal, Vol. 101, No. 849, 1988, pp. 453-455

[21] I. Arad, F. Eyal and P. Fainmesser, "Umbilical Care and Cord Separation," Archives of Disease in Childhood, Vol. 56, No. 11, 1981, pp. 887-888.

[22] K. Rais-Bharami, E. B. Schulte and M. Naqv, "Postnatal Timing of Spontaneous Umbilical Cord Separation,” American Journal of Perinatology, Vol. 10, No. 6, 1993 pp. 453-454.

[23] L. C. Mullany, G. L. Darmstadt, S. K. Kharty, J. Katz, S. C. LeClerq, S. Shrestha, R, Adhikari and J. M. Tielsch, "Topical Applications of Chlorhexidine to the Umbilical Cord for Prevention of Omphalitis and Neonatal Mortality in Southern Nepal: A Community Based, Cluster-Randomised Trial,” Lancet, Vol. 367, No. 9514, 2006, pp.
910-918. doi:10.1016/S0140-6736(06)68381-5

[24] R. Howard, "The Appropriate Use of Topical Antimicrobials and Antiseptics in Children," Pediatric Annals, Vol. 30, No. 4, 2001, pp. 219-224.

[25] G. A. Oyedeji, O. A. Oyedeji, P. O. Elemile and V. I. JoelMedewase, "Cord Care Practices of South-Western Nigerian Mothers," International Journal of Tropical Medicine, Vol. 3, No. 2, 2008, pp. 15-18.

[26] A. Thind and A. M. Cruz, "Determinants of Children's Health Service Utilization in the Phillipines," Journal of Tropical Pediatrics, Vol. 49, No. 23, 2003, pp. 260-273.

[27] T. Jaja, P. I. Opara and B. E. Otaigbe, "Health Care Seeking Behavior for Childhood Illnesses in Port Harcourt, Southern Nigeria,” The Nigerian Health Journal, Vol. 10, No. 3-4, 2010, pp. 43-47

[28] A. Dawodu, "Neonatology in Developing Countries; Problems, Practices and Prospects," Annals of Tropical Paediatrics, Vol. 18, 1998, pp. S73-S79.

[29] J. Aubel, “Grandmothers: A Learning Institution,” Creative Associates and USAID, 2005.

[30] M. Van Zyl, “The Ekwendeni Agogo Approach: Grandparents as Agents of Change for Newborn Survival," Healthy Newborn Network, 2010. http://www.healthynewbornnetwork.org

[31] J. Abel, I. Toure and M. Diagne, "Senegalese Grandmothers Promote Improved Maternal and Child Health Nutrition Practices: The Guardians of Tradition Are Not Averse to Change," Social science and Medicine Vol. 59, No. 5, 2004, pp. 945-959. doi:10.1016/j.socscimed.2003.11.044 